\title{
A biaxial test for rheological and formability identification
}

\author{
I. Zidane, D. Guines ${ }^{\mathrm{a}}$, L. Léotoing, and E. Ragneau \\ Université Européenne de Bretagne, INSA-LGCGM - EA3913, 20 avenue des Buttes de Coësmes, \\ CS 70 839, 35708 Rennes Cédex 7, France
}

\begin{abstract}
Accurate constitutive laws and formability limits of materials are essential for a numerical optimization of sheet forming processes. The main objective of this work is to develop a new experimental device able to give for a unique specimen a good prediction of rheological parameters and formability under conditions (low and intermediate strain rates) close to the ones met in processes. The proposed device is a servo-hydraulic testing machine provided with four independent dynamic actuators allowing biaxial tensile tests on a dedicated specimen. By localizing necking in the central zone of the specimen, the strain path in this zone is controlled by the speed ratio between the two axes and the whole forming limit curve can be covered. Such a specimen is proposed through a numerical and experimental validation procedure. Finally, an experimental forming limit curve for the aluminium alloy AA5086 is determined thanks to a rigorous procedure for detecting the onset of necking in the specimen.
\end{abstract}

\section{Introduction}

Metal forming operations are carried out under multi-axial states of stress, then limiting the mechanical behaviour identification of materials to uniaxial tensile tests can lead to a misrepresentation of this behaviour. The use of a more realistic loading during identification tests such as biaxial loading conditions must lead to a more accurate representation of the expected behaviour of the material. For the evaluation of formability, the well-known method consists in plotting a forming limit diagram (FLD) for a given material. In order to overcome the drawbacks of the classical tests, like the Marciniak test or Nakazima test, a cruciform specimen can be an interesting alternative if the strain path at the onset of necking is directly controlled by the testing speed of each actuator of the biaxial machine, independently from the specimen shape and without any friction effects. Moreover, this device is well adapted to conduct tests under dynamic conditions and then evaluate the effect of strain rate on formability of materials. Strain rate sensitivity has been identified as an important factor for determining formability and can alter significantly the level and shape of forming limit curves. However, to date, very few studies have been done to characterize the forming behavior of sheet metals in a large range of strain rates, mainly due to a lack of reliable experimental data.

In this study, an experimental device developed to realize in-plane biaxial tensile tests on sheet specimens is presented. The proposed device permits to perform experiments under static and dynamic conditions allowing material characterizations at low and intermediate strain rates. For this biaxial test, a specific cruciform specimen shape is defined and optimized. Then, from the defined geometry, experiments are realized on 5086 aluminium alloy in order to identify from a unique specimen both formability limits and the whole elasto-plastic behaviour of metallic sheets including hardening and anisotropic behaviour.

a e-mail: dominique.guines@insa-rennes.fr

This is an Open Access article distributed under the terms of the Creative Commons Attribution-Noncommercial License 3.0, which permits unrestricted use, distribution, and reproduction in any noncommercial medium, provided the original work is properly cited. 


\section{Biaxial experimental device}

\subsection{Biaxial testing machine and performances}

The developed test machines to produce biaxial loading on cruciform specimen are either stand-alone biaxial testing machines or link mechanism attachments for biaxial testing.

The device designed by Makinde et al. [1] consisted of four hydraulic actuators with a capacity of $250 \mathrm{kN}$. Two actuators were used on each axis to ensure that the center of the specimen did not move during testing. The results from this research were used to develop an optimum specimen for low strains. Using the same testing apparatus Green et al. [2] have investigated the elasto-plastic behavior of an 1145 aluminium sheet alloy. Flat cruciform specimens have been tested under in-plane biaxial loading conditions to obtain both the plastic work contours and the biaxial flow curves. A further stand-alone device developed by Boehler et al. [3] consisted of four double acting screw driven pistons, mounted on an octogonal vertical frame. The test speed varies between 0.003 and $0.3 \mathrm{~mm} / \mathrm{min}$. The optimized specimen is performed to identify anisotropic elastic behavior. Shimamoto et al. [4] have developed a hydraulic biaxial testing system to perform both dynamic and static tests. From dynamic tests, they investigate the crack extension behavior on an aluminium alloy (A7075-T6) at $1000 \mathrm{~mm} / \mathrm{s}$.

In an attempt to reduce the cost associated with building stand-alone test machines, standard tensile or compressive devices have been converted to biaxial test setup (Hoferlin et al. [5], Mohr and Mulalo [6], Ferron and Makinde [7]). Nevertheless, link mechanism attachments for biaxial testing machines seem not very efficient to study the forming limits under various and complex loading paths which would require to change the geometry of the system for each path. Moreover, in such experimental devices, both high stiffness and natural frequencies are expected so these systems are not appropriate for biaxial tests and particularly dynamic ones.

Stand-alone testing machines are well adapted to realize biaxial tests and more particularly to obtain different strain paths or various stress states of biaxial tension by changing the proportion of loads or displacements of the two axes. Moreover, to perform both static and dynamic tests with the same device, hydraulic technology is more appropriated, by using pump pressure or accumulator pressure for static tests and instantaneously releasing a great quantity of high-pressure flow accumulated for dynamic tests.

In this work, a servo-hydraulic testing machine provided with four independent dynamic actuators has been used (Figure 1). The center point of the specimen is always maintained stationary throughout the test by an efficient servo-hydraulic control. For each actuator, the loading capacity is $50 K N$ and the maximum velocity can reach up $2 \mathrm{~m} / \mathrm{s}$. The load on each axis is measured by two specific gage sensors placed between the grip and actuator rod (Figure 2).

Before the design stage of this machine, one important requirement was the synchronization at impact of the four actuators for which the absolute displacement difference must be less than $0.5 \mathrm{~mm}$. This point is always verified on this machine as illustrated in Figure 3 where the displacement of the central point during test for a specimen tested at a velocity of $1 \mathrm{~m} / \mathrm{s}$ for each actuator is plotted. The trajectory of this point is held in a $0.2 \mathrm{~mm}$ by $0.2 \mathrm{~mm}$ window size.

\subsection{Cruciform specimen shape}

In order to determine the forming limits under complex loading paths, a specimen shape has been defined. The main difficulty to design an appropriate cruciform specimen shape consists in forcing the onset of necking in the central zone and not in the arms of the specimen. Although cruciform specimens have been investigated quite extensively, no standard geometry exists to this day [8] and the design of the specimen shape remains the main difficulty for biaxial tensile tests. Moreover, for dynamic tests, the maximum stiffness of the specimen, the initial one, has 


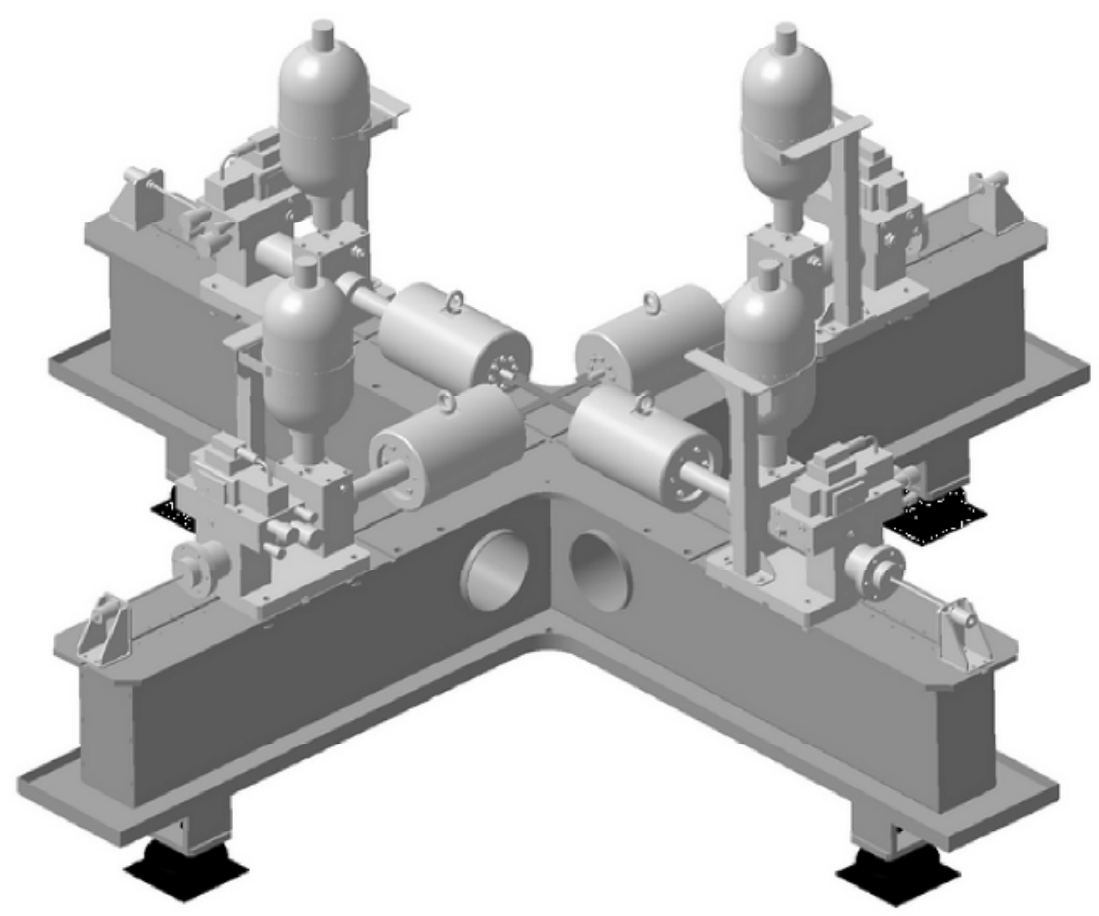

Fig. 1. Servo-hydraulic testing machine.

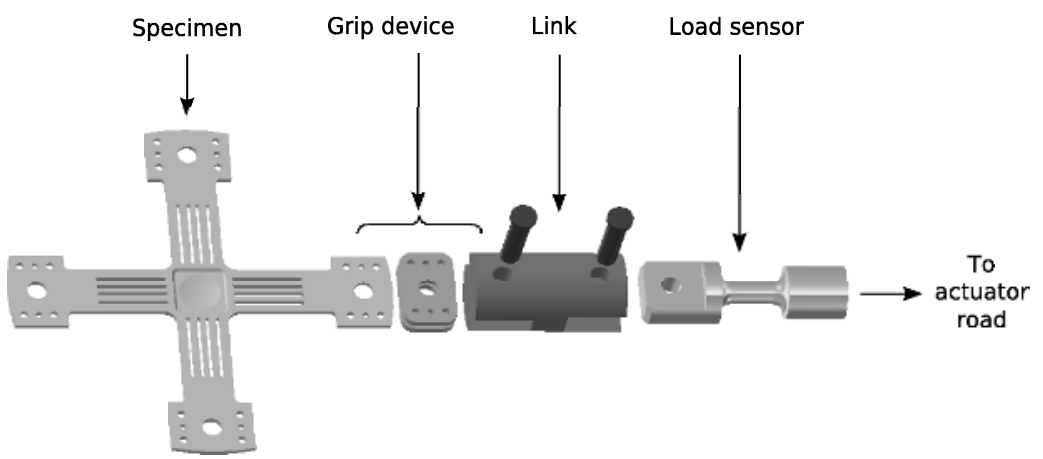

Fig. 2. Grip device for each actuator.

to be adjusted according to the experimental setup capacities in order to control tensile test velocities. For the considered experimental device, the stiffness of the specimen should not exceed $45 \mathrm{kN} / \mathrm{mm}$ at $1 \mathrm{~mm} / \mathrm{s}$ for dynamic tests. Others considerations like manufacturing constraints must also be taken into account.

To ensure that necking always appears in the central zone, the design of the cruciform specimens must induce the greatest deformations in the central zone and no strain localizations in the other areas (grooves, fillets, ...). From finite element simulations, different specimen geometries have been investigated. The more effective and the more promising specimen shape has been optimized in order to make efficient its use for a whole forming limit curve identification [9]. The cruciform specimen shape obtained at the end of the optimization stage is presented Figure 4. For this geometry, the strain path value at the central point of the 


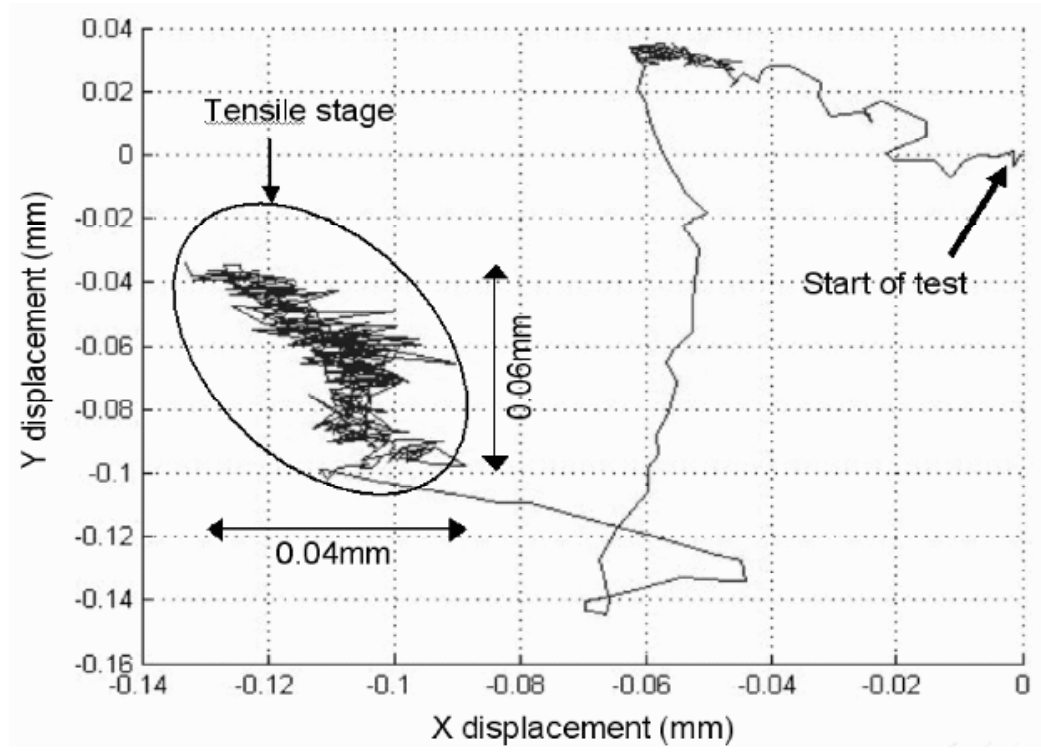

Fig. 3. Central point displacement.

specimen is directly linked to the velocity ratio of actuators. At the end of the test, for the onset of necking, the strain path remains constant for all speed ratios.

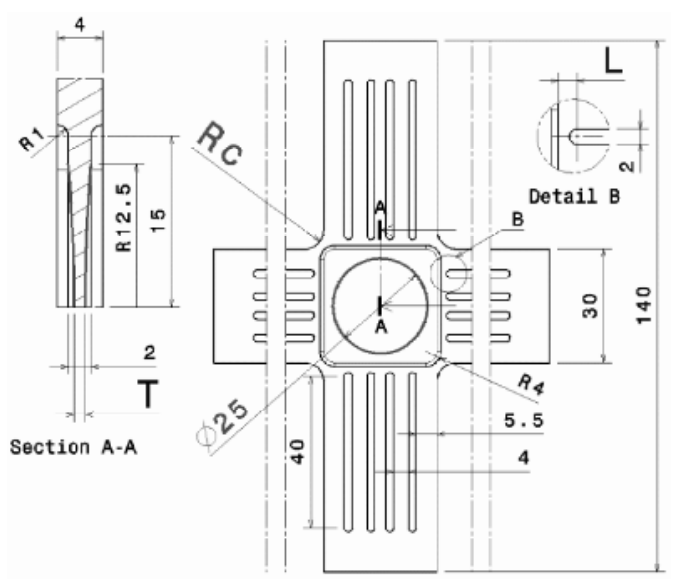

Fig. 4. Specimen shape.

\subsection{Strain measurement}

The Digital Image Correlation technique (DIC) is used to evaluate the strain components during the experiments. To capture the consecutive images during the test, a Fastcam ultima APX-RS digital CMOS camera associated with a macro lens is used. The maximum acquisition rate is $3000 \mathrm{i} / \mathrm{s}$ for a $1024 \times 1024$ pixels full resolution range. For the specimen geometry defined above, the dimensions of the filmed central zone are about $30 \times 30 \mathrm{~mm}$. A resolution of $512 \times 512$ 
pixels and an acquisition of 500i/s are used during the tests. The commercial digital imaging program CORRELA2006, developed by LMS at the University of Poitiers, is employed to perform correlation analysis in this work. The DIC program evaluates the surface strains of the specimen.

\section{Results}

In order to validate the experimental device presented above and to show the capabilities of the proposed biaxial test, the anisotropic elasto-plastic behavior and formability limits of a 5086 aluminium alloy are identified. Different strain path, directly controlled by displacements imposed on each axis of the specimen, have been performed in order to cover the whole forming limit curve. For each biaxial tensile test, the experimental measures are the load versus displacement curves on each axis of the cruciform specimen and the displacement or strain surface fields in the central zone.

\subsection{Rheological behavior identification}

The anisotropic elasto-plastic behavior of the 5086 aluminium alloy is identified by means of an inverse procedure using the experimental data of the equi-biaxial test. Material parameters (constants of both hardening law and anisotropic yield criteria) are identified from the global measurement of forces and with the local measurement of strain fields. From the DIC software, the surface strains are evaluated and the strain thickness is calculated assuming the incompressibility condition during plastic work. Then, an experimental equivalent plastic strain can be determined and used in the identification procedure.

The experimental data obtained for the equi-biaxial tensile test (a velocity of $1 \mathrm{~mm} / \mathrm{s}$ is imposed by each actuator) are presented Figure 5. From these experimental data and a FE model of the equi-biaxial tensile test, an inverse procedure of identification is carried out to determine the set of material parameters. The identification procedure used in the present work is based on a gradient Gauss-Newton algorithm to solve the optimization problem. The best set of parameters is obtained by minimizing the difference in a least-square sense between the experimental force and equivalent plastic strain versus time curves and the FE calculated ones. The commercial software package ABAQUS is used to simulate the equi-biaxial tensile test.

In the FE modelling of the biaxial tensile test, the elastic part of the aluminium alloy behavior is described by Hooke's model with Young modulus, $E=67293 \mathrm{MPa}$ and Poisson ratio, $\nu=0.3$. For the plastic part, an anisotropic Hill48 yield criteria is considered and the hardening behavior is described by a Ludwick's law:

$$
\bar{\sigma}=\bar{\sigma}_{0}+\mathrm{K} \bar{\varepsilon}^{\mathrm{n}}
$$

where $\bar{\sigma}$ and $\bar{\varepsilon}$ are the equivalent stress and the equivalent plastic strain respectively, $\bar{\sigma}_{0}$ is the Yield stress obtained from a mono-axial tensile test.

The identification results for the proposed constitutive equation and anisotropic yield criteria are given in table 1. A comparison between the experimental and calculated force and equivalent plastic strain versus time curves is presented Figure 5.

Table 1. Identified material parameters.

\begin{tabular}{ccccccc}
\hline $\bar{\sigma}_{0}$ & $K(\mathrm{MPa})$ & $n$ & $F$ & $G$ & $H$ & $N$ \\
\hline 139.6 & 300. & 0.33 & 0.67 & 0.62 & 0.38 & 1.31
\end{tabular}



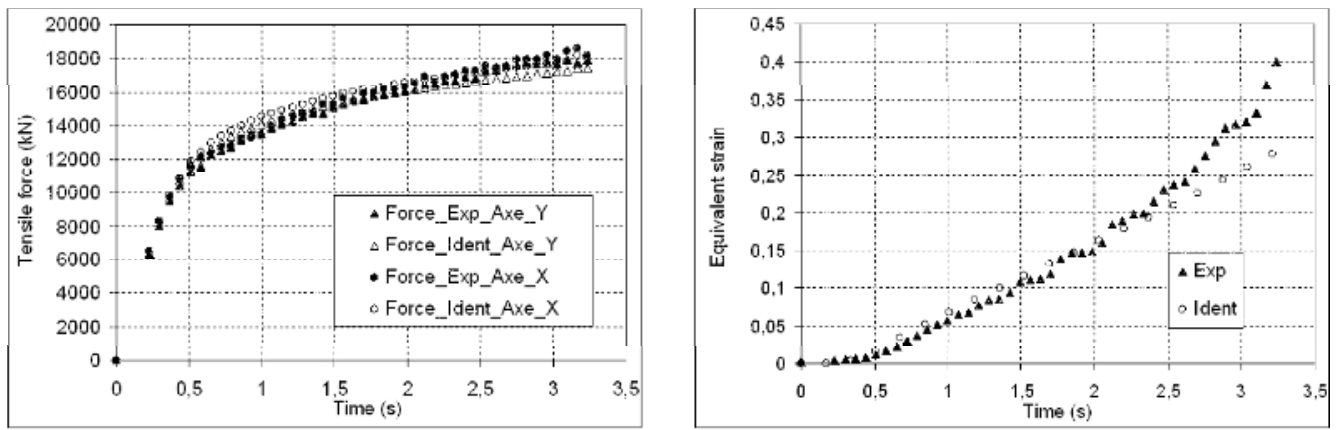

Fig. 5. Identification results.

\subsection{Experimental and numerical forming limit curve}

The same procedure is applied for the detection of numerical and experimental forming limit strains. When the equivalent plastic strain increment ratio between a point in a central position and a point in an adjacent zone reaches a critical value, the onset of localized necking is assumed to occur and the corresponding major and minor strains calculated at the central point are reported on the Forming limit Diagram. The main difficulty consists in rigourously fixing the level of the ratio critical value ([10], [9]).

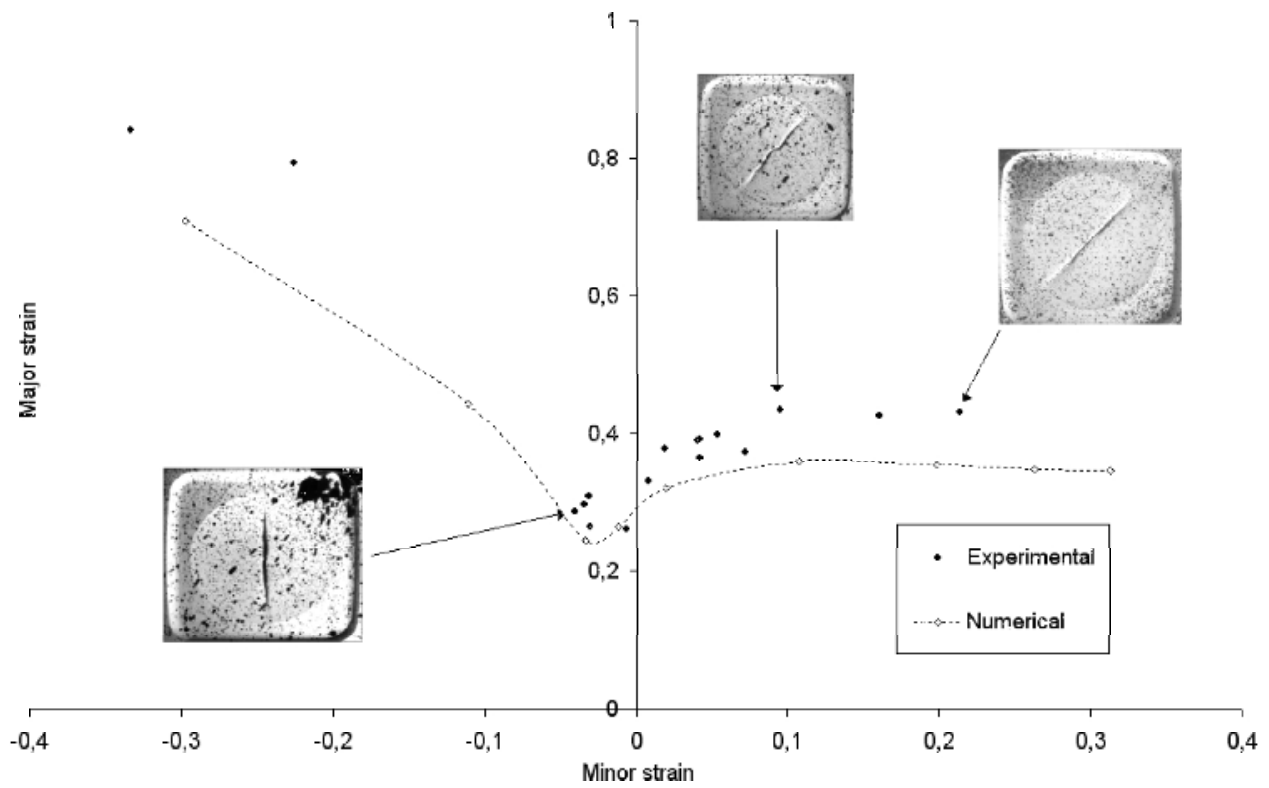

Fig. 6. Experimental and numerical formability of AA5086.

Figure 6 presents a comparison between the experimental and numerical formability of AA5086. One can see that the above described procedure is successfully used to plot experimental and numerical forming limit curves. The correlation is rather good, especially for the values of minor strain close to zero which is the zone of major interest for a FLC. The minimum 
of the FLC is not exactly reached for a zero value of the minor strain, this well known effect is due to the non-linearity of the strain path at the beginning of the test. Besides, different initial directions of fracture can be observed but in all cases, the initial stage takes place in the center of the specimen.

\section{Conclusions and perspectives}

The presented biaxial experimental device associated with a dedicated cruciform specimen is successfully used for a complete elasto-plastic characterization of the metallic sheet behavior of an aluminium alloy. The strain path controlled by displacements of actuators permits to cover the whole forming limit diagram. A good correlation between experimental and numerical results is shown, so the identified elasto-plastic behavior seems to be adapted for the numerical prediction of the forming limit curve, especially for large strains. The procedure, validated in quasi-static conditions, is now successfully adapted in dynamic ones in order to evaluate the influence of strain rate on formability.

\section{References}

1. A. Makinde, L. Thibodeau, and K.W. Neale. Development of a apparatus for biaxial testing for cruciform specimens. Exp. Mech., 32:138-144, 1992.

2. D.E. Green, K.W. Neale, S.R. MacEven, A. Makinde, and R. Perrin. Experimental investigation of the biaxial behavior of an aluminium sheet. International journal of plasticity, 20:1677-1706, 2004.

3. J.P. Boehler, S. Demmerle, and S. Koss. A new direct biaxial testing machine for anisotropic materials. Exp. Mech., pages 1-9, 1994.

4. A. Shimamoto, T. Shimomura, and J. Nam. The development of a servo dynamic loading device. Key Eng. Mater., 243-244:99-107, 2003.

5. E. Hoferlin, A. Van Bael, P. Van Houtte, G. Steyaert, and C. De Maré. The design of a biaxial tensile test and its use for the validation of cristallographic yield loci. Modelling Simulat. Mater. Sci., 8:423-433, 2000.

6. D. Mohr and D. Mulalo. Experimental investigation on the plasticity of hexagonal aluminium honeycomb under multiaxial loading. J. Appl. Mech., 71:375-385, 2004.

7. G. Ferron and A. Makinde. Design and development of a biaxial strength testing device. J. Test. Evaluat., 16:253-256, 1988.

8. A. Hannon and P. Tiernan. A review of planar biaxial tensile test systems for sheet metal. Journal of materials processing technology, 198:1-8, 2008.

9. I Zidane D Guines L Léotoing E Ragneau. Development of an in-plane biaxial test for forming limit curve (FLC) characterization of metallic sheet. Measurement science and technology, 2010.

10. I ZIDANE. Développement D'un Banc D'essai de Traction Biaxiale Pour la Caractérisation de la Formabilité et Du Comportement Élastoplastique de Tôles Métalliques. PhD thesis, Institut National des Sciences Appliquées de Rennes, France, 2009. 